\title{
Neuroticism Behaviour between Individual Game Players and Team Game Players- A Comparative Analysis
}

\author{
Chiranjib Sarkar ${ }^{1}$, Gaurav Pant ${ }^{2}$ \\ ${ }^{1}$ M.Phil Scholar, Department of Physical Education, Bharati Vidyapeeth Deemed University, Pune, India \\ ${ }^{2}$ Assistant Professor, Department of Physical Education, Bharati Vidyapeeth Deemed University, Pune, India'
}

\begin{abstract}
Background: Neuroticism is a long-term tendency to be in a negative emotional state. People with neuroticism tend to have more depressed moods - they suffer from feelings of guilt, envy, anger and anxiety, more frequently and more severely than other individuals. Neuroticism is the state of being neurotic.

Purpose: The purpose of this study is to compare the neuroticism behaviour between individual game players and team game players.

Setting and Design: The subjects taken for this study were 100 male students (50 individual game players \& 50 team game players) from various colleges of Bharati Vidyapeeth Deemed University, age ranging from 20-26 years. Questionnaire was used as a tool for this survey.

Methods: The current study was performed on the Neuroticism Behaviour of Individual game players and Team game players; the collected data for the study were assessed on the scoring and norms according to the Medico-Psychological Questionnaire $(M P Q)$.

Statistical Techniques: Independent ' $t$ '-test was applied to find out the comparison of neuroticism behaviour between individual game players and team game players.

Result: There was significant difference have found in neuroticism behaviour among the selected two groups of male individual game players and team game players.

Conclusion: The results conclude that individual game players who scored high on neuroticism are more likely than the average to experience such feelings as anxiety, anger, envy, guilt, and depressed mood and team game players who scored low on neuroticism are more emotionally stable than the individual game players.

Key Words: Neuroticism behaviour, Individual game players, Team game players.
\end{abstract}

\section{Introduction}

1.1 Background of the study:Neuroticism is a fundamental personality trait in the study of psychology characterized by anxiety, fear, moodiness, worry, envy, frustration, jealousy, and loneliness. Individuals who score high on neuroticism are more likely than the average to experience such feelings as anxiety, anger, envy, guilt, and depressed mood. They respond more poorly to stressors, are more likely to interpret ordinary situations as threatening, and minor frustrations as hopelessly difficult. They are often self-conscious and shy, and they may have trouble controlling urges and delaying gratification. Neuroticism is a prospective risk factor for most "common mental disorders", such as depression, phobia, panic disorder, other anxiety disorders, and substance use disorder-symptoms that traditionally have been called neuroses.

Research has found that a wide range of clinical mental disorders are associated with elevated levels of neuroticism compared to levels in the general population. Disorders associated with elevated neuroticism include mood disorders, such as depression and bipolar disorder, anxiety disorders, eating disorders, schizophrenia and schizoaffective disorder, dissociative identity disorder, and hypochondriasis. Mood disorders tend to have a much larger association with neuroticism than most other disorders. Personality disorders as listed in DSM-IV in general tend to be associated with elevated neuroticism. A meta-analysis found that Borderline, Paranoid, Schizotypal, Avoidant, and Dependent Personality disorders were each associated with substantial levels of neuroticism. The remaining personality disorders had either modest positive or non-significant (in the case of narcissistic and histrionic) associations with neuroticism.

1.2 The problem and its social relevance: Neuroticism appears to be related to physiological differences in the brain. One of the theories regarding evolutionary approaches to depression focuses on neuroticism. A moderate amount of neuroticism may provide benefits, such as increased drive and productivity, due to greater sensitivity to negative outcomes. Too much, however, may reduce fitness by producing, for example, recurring depressions. Thus, evolution will select for an optimal amount and most people will have neuroticism near this optimum. However, because neuroticism likely has a normal distribution in the population, a minority will be highly neurotic. 
Self-deprecating comedians and complainers wear their neuroticism as a badge of honor. In truth, the negatively biased are more prone to depression, anxiety, self-consciousness and hypochondria, to name just a few behavioral tripwires. Neuroticism is no fun for anyone. The good news: all personality traits, including emotional instability, exist on a continuum, in this case from the very neurotic to the implacably stable. Neuroticism is the condition or psychological trait of being neurotic. In modern life we should know about Neuroticism personality. This study measured the hysteria, neurasthenia, anxiety neurosis, compulsion and mentally illness of individuals.

1.3 Hypothesis: There may be no significant differences in neuroticism behavior among the selected two groups of male individual game players and team game players.

\section{Method}

2.1 Subjects: A total number of 100 male students (50 individual game players \& 50 team game players) were selected randomly from various colleges of Bharati Vidyapeeth University and their ages were ranged from 2026 years.

2.2 Variables of the study: Although only one variable i.e., neuroticism behavior has been included in this study, the five factors were tested as follows:

- Hysteria

- Anxiety Neurosis

- Neurasthenia

- Reactive Depression

- Obsession Compulsion

2.3 Tool used: Medico-Psychological Questionnaire (MPQ) constructed by J. Bharath Raj was the tool for the present study. The reliability and validity of the test are respectively +0.71 and +0.68 .

2.4 Procedure: A total number of 100 male students (50 individual game players \& 50 team game players) were selected randomly from various colleges of Bharati Vidyapeeth University to conduct the test.The test was conducted through the questionnaire on both groups. They were given the questionnaire separately and thus the data were collected.

\section{Result}

The detailed analysis of the data is presented in this chapter. The data collected from the subject were arranged in a tabular form and to find out the significant difference. Independent t-test with level of significance was set at 0.05 were used. The entire analysis of the data was done on the basis of the objective of the study. The data was obtained by administrating under the comparative analysis of neuroticism behaviour between individual game players and team game players.

3.1 Level of significance: Primarily the data was analyzed using descriptive statistics such as mean, standard deviation etc. and independent ' $t$ '-test was used to compare the neuroticism behaviour between individual game players and team game players. The level of significant difference was set at 0.05 levels.

3.2 Findings: The statistical results of the hysteria, neurasthenia, anxiety neurosis, reactive depression, obsession compulsion and comparison of neuroticism behaviour have been presented in tables 1 to 6 .

Table: 01: Comparison of hysteria between Team game players and Individual game players

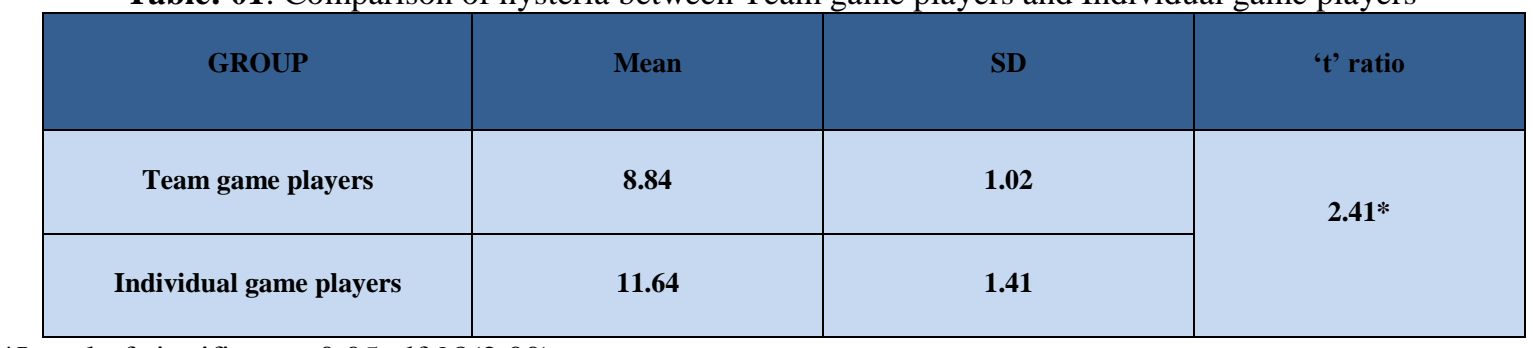

*Level of significance 0.05 , df 98(2.00).

The above table shows the mean of team game players (8.84) and individual game players (11.64), slandered deviations (1.02\& 1.41) and the calculated t-ratio 2.41 at the degree of freedom 98(2.00). Since the tabulated t-ratio 2.00, there is significant difference between Individual game players and Team game players in relation to hysteria. 


\section{GRAPHICAL REPRESENTATION OF HYSTERIA BETWEEN TEAM GAME PLAYERS AND INDIVIDUAL GAME PLAYERS}

Figure- 1

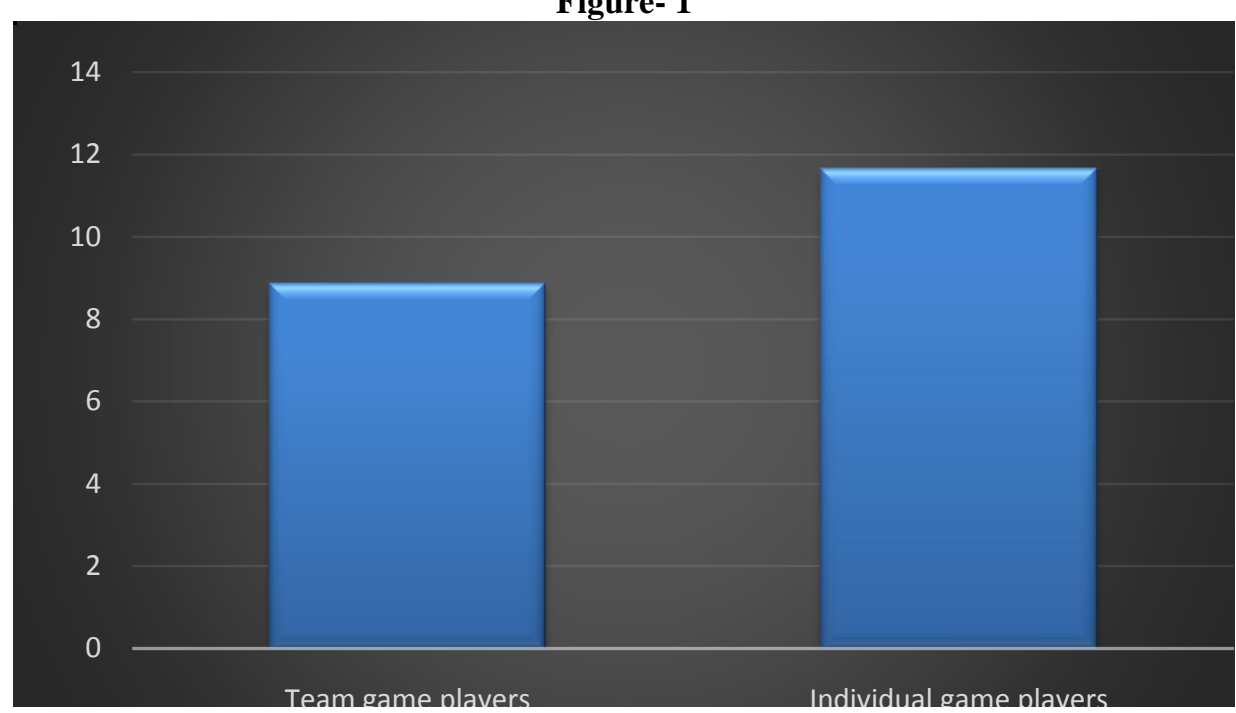

Table: 02: Comparison of neurasthenia between Team game players and Individual game players

\begin{tabular}{|c|c|c|c|}
\hline GROUP & Mean & SD & 't' ratio \\
\hline Team game players & 8.46 & 1.13 & $3.80 *$ \\
\hline Individual game players & 17.34 & 1.68 & \\
\hline
\end{tabular}

*Level of significance 0.05 , df 98(2.00).

The above table shows the mean of team game players (8.46) and individual game players (17.34), standered deviations $(1.13 \& 1.68)$ and the calculated t-ratio 3.80 at the degree of freedom $98(2.00)$. Since the tabulated tratio 2.00, there is significant difference between Team game players and Individual game players in relation to neurasthenia.

\section{GRAPHICAL REPRESENTATION OF NEURASTHENIA BETWEEN TEAM GAME PLAYERS AND INDIVIDUAL GAME PLAYERS}

Figure- 2

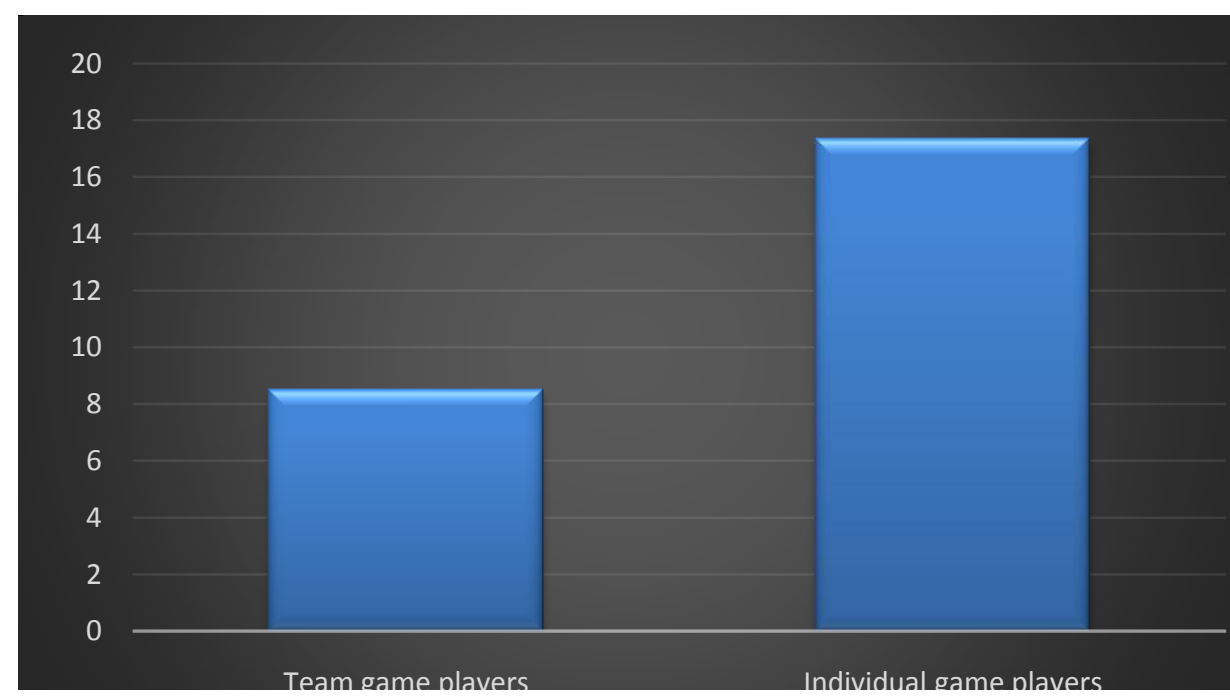


Table: 03: Comparison of anxiety neurosis between Team game players and Individual game players

\begin{tabular}{|c|c|c|c|}
\hline GROUP & Mean & SD & 't' ratio \\
\cline { 1 - 3 } Team game players & 8.44 & 1.11 & \multirow{2}{*}{$1.54 *$} \\
\hline Individual game players & 17.34 & 1.69 & \\
\hline
\end{tabular}

*Level of significance 0.05 , df $98(2.00)$.

The above table shows the mean of Team game players (8.44) and Individual game players (17.34), standered deviations $(1.11 \& 1.69)$ and the calculated t-ratio 1.54 at the degree of freedom 98(2.00). Since the tabulated t-ratio 2.00, there is no significant difference between Individual game players and Team game players in relation to anxiety neurosis.

\section{GRAPHICAL REPRESENTATION OF ANXIETY NEUROSIS BETWEEN TEAM GAME PLAYERS} AND INDIVIDUAL GAME PLAYERS

Figure- 3

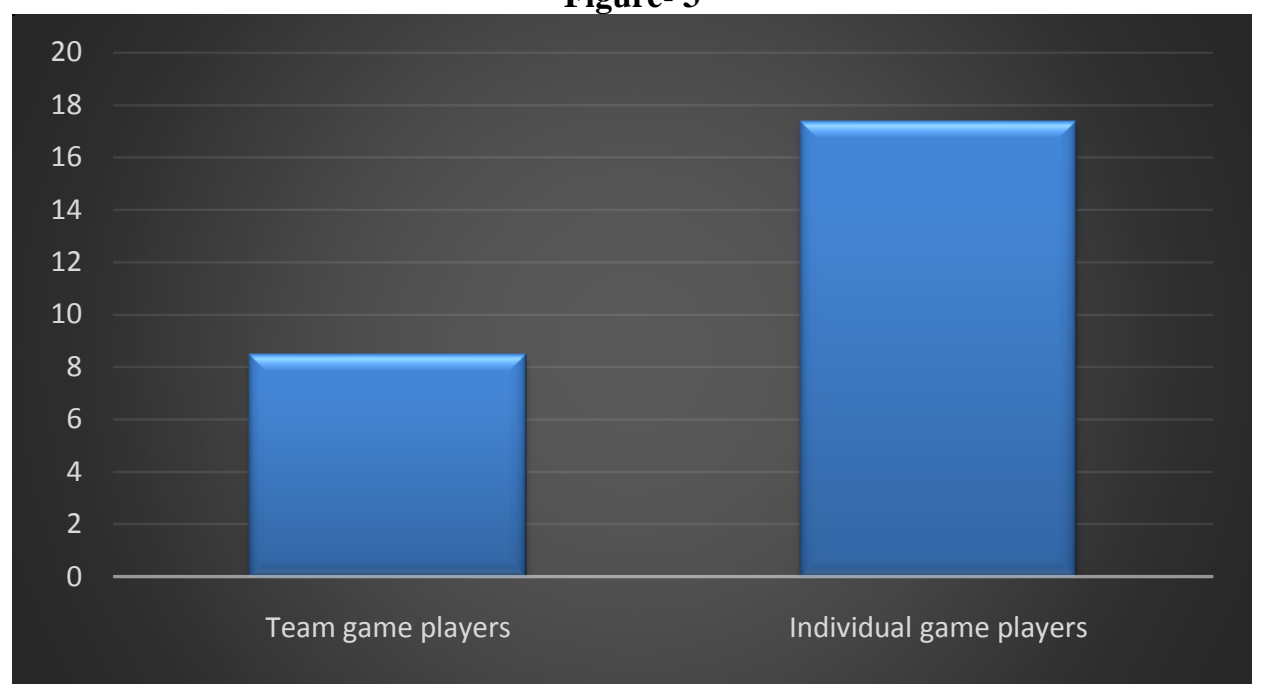

Table: 04: Comparison of reactive depression between Team game players and Individual game players

\begin{tabular}{|c|c|c|c|}
\hline GROUP & Mean & SD & 't' ratio \\
\hline Team game players & 17.4 & 1.76 & $3.28^{*}$ \\
\hline Individual game players & 25.42 & 2.44 & \\
\hline
\end{tabular}

*Level of significance 0.05 , df 98(2.00).

The above table shows the mean of Team game players (17.4) and Individual game players (25.42), standered deviations $(1.76 \& 2.44)$ and the calculated t-ratio 3.28 at the degree of freedom 98(2.00). Since the tabulated t-ratio 2.00, there is significant difference between Team game players and Individual game players in relation to reactive depression. 


\section{GRAPHICAL REPRESENTATION OF REACTIVE DEPRESSION BETWEEN TEAM GAME PLAYERS AND INDIVIDUAL GAME PLAYERS}

Figure- 4

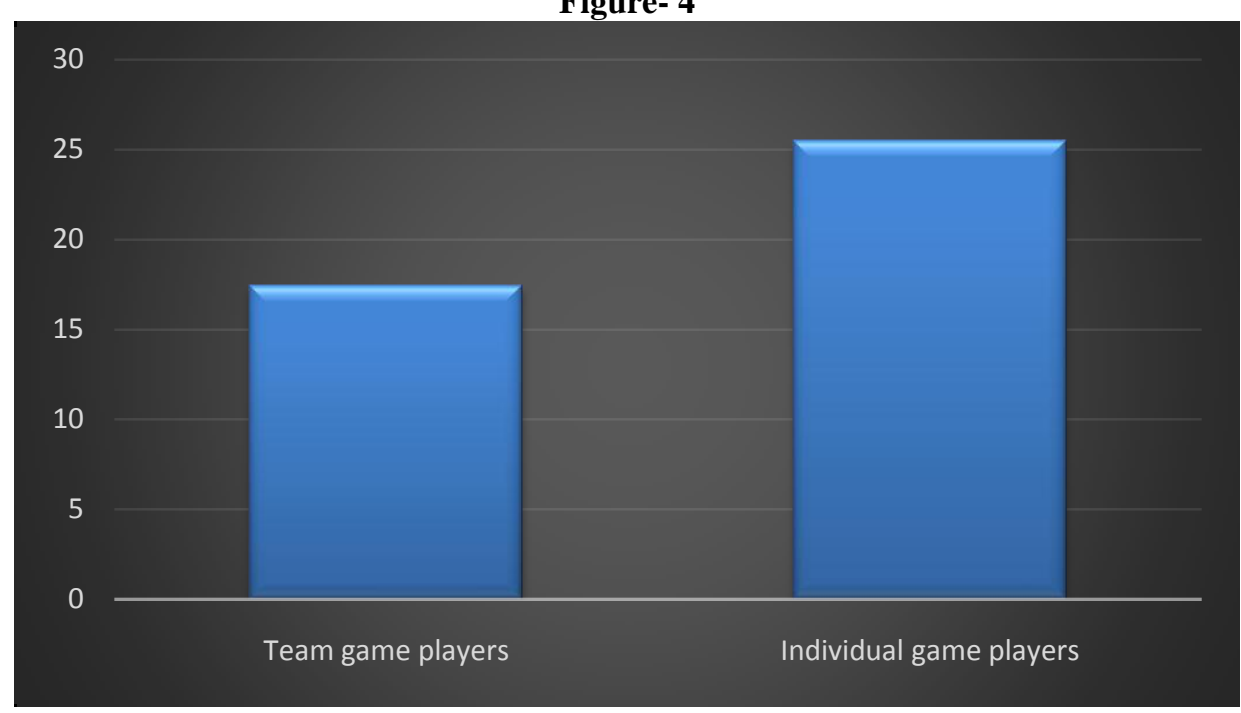

Table: 05: Comparison of obsession compulsion between Team game players and Individual game players

\begin{tabular}{|c|c|c|c|}
\hline GROUP & Mean & SD & ' $t$ ' ratio \\
\hline Team game players & 7.32 & 1.66 & \multirow{2}{*}{$3.11 *$} \\
\hline Individual game players & 11.92 & 1.54 & \\
\hline
\end{tabular}

*Level of significance 0.05 , df 98(2.00).

The above table shows the mean of Team game players (7.32) and Individual game players (11.92), standered deviations (1.66\& 1.54) and the calculated t-ratio 3.11 at the degree of freedom 98(2.00). Since the tabulated t-ratio 2.00, there is significant difference between Team game players and Individual game players in relation to obsession compulsion.

\section{GRAPHICAL REPRESENTATION OF OBSESSION COMPULSION BETWEEN TEAM GAME PLAYERS AND INDIVIDUAL GAME PLAYERS \\ Figure- 5}

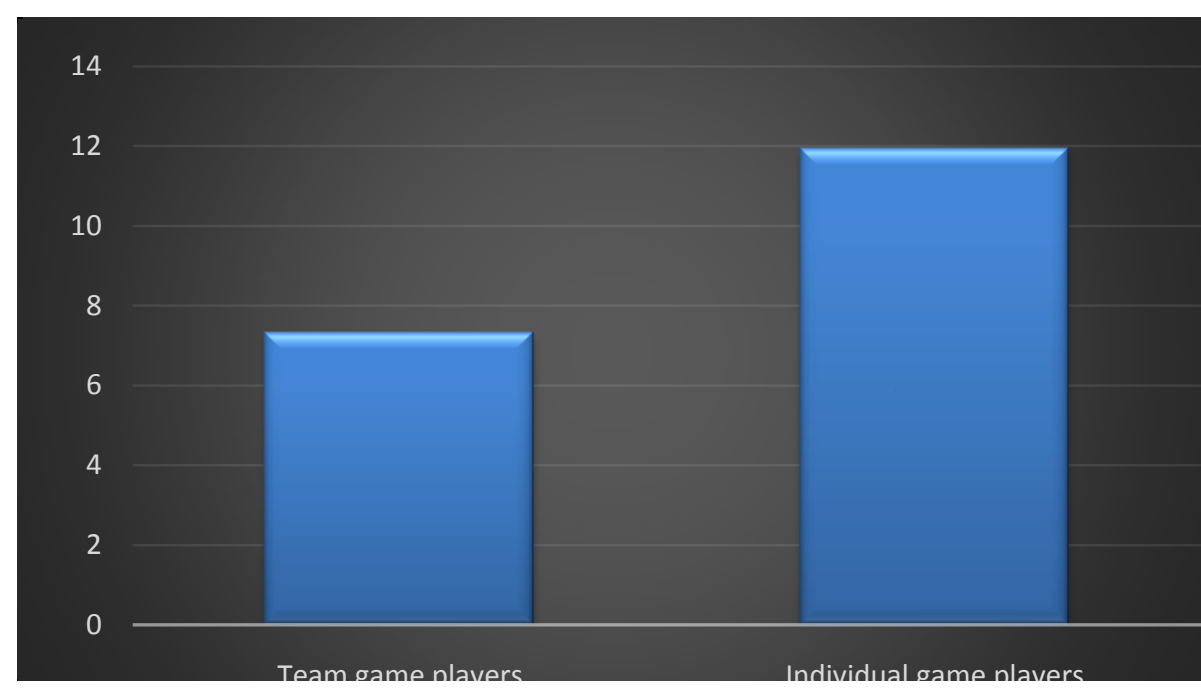


Table: 06

Comparison of neuroticism behaviour between Team game players and Individual game players

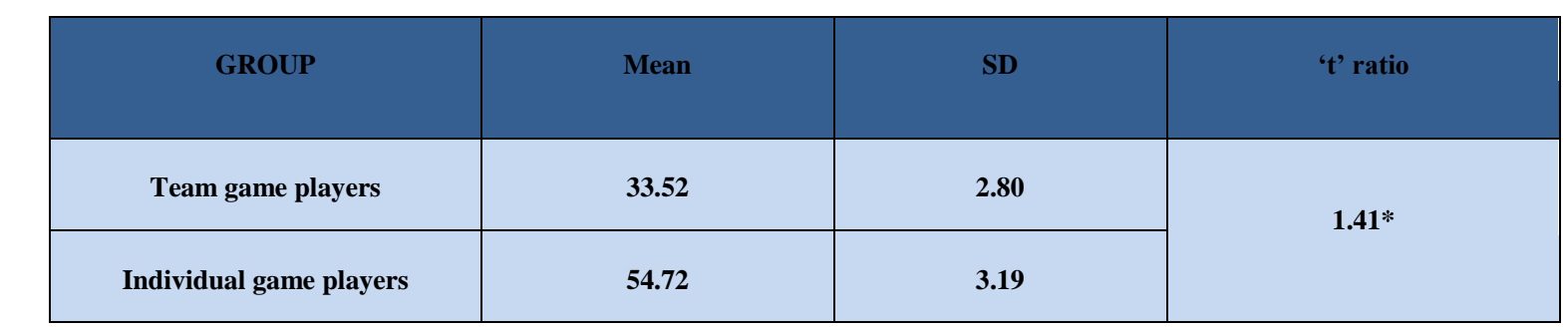

*Level of significance 0.05 , df $98(2.00)$.

The above table shows the mean of Team game players (33.52) and Individual game players (54.72), standered deviations $(2.80 \& 3.19)$ and the calculated t-ratio 1.41 at the degree of freedom 98(2.00). Since the tabulated t-ratio 2.00, there is no significant difference between team game players and individual game players in relation to neuroticism behaviour.

\section{GRAPHICAL REPRESENTATION OF NEUROTICISM BEHAVIOUR BETWEEN TEAM GAME PLAYERS AND INDIVIDUAL GAME PLAYERS.}

Figure- 6

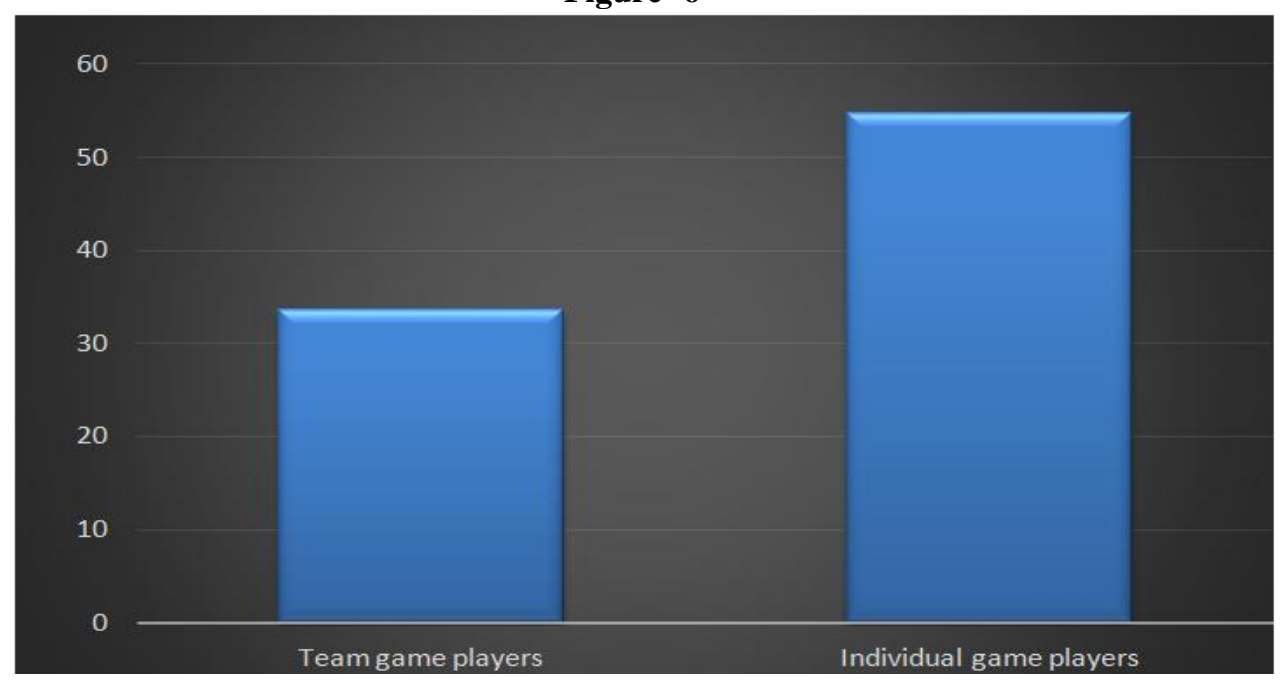

3.3 Discussion of hypothesis: There is no significant difference have found in neuroticism behaviour among the selected two groups of male individual game players and team game players, so hypothesis is accepted.

\section{Conclusion}

The results of the study indicate that there was no significant difference have found in neuroticism behaviour among the selected two groups of male Individual game players and Team game players in case researcher hypothesis is accepted. Individual game players who scored high on neuroticism are more likely than the average to experience such feelings as anxiety, anger, envy, guilt, and depressed mood and Team game players who scored low on neuroticism are more emotionally stable than the Individual game players.

According to Paulus DJet al. (2015) the association between neuroticism and depression. However, neuroticism is a general risk factor associated with many forms of psychopathology, such as anxiety, eating, and personality disorders. Past research has suggested that other factors may mediate the relationship between neuroticism and symptoms of particular disorders. Self-report questionnaires measuring neuroticism, emotion dysregulation, psychological inflexibility, shame, and symptoms of depression were administered to 105 inpatient adolescents (aged 12-17). The current study examined three factors (emotion dysregulation difficulties, psychological inflexibility, and shame) as concurrent mediators of the neuroticism/depression association.Neuroticism were significantly associated with depression, as expected. Neuroticism was also associated with emotion dysregulation and psychological inflexibility, which, in combination, fully mediated the association between neuroticism and depression. Shame was not significantly associated with neuroticism or depression, when controlling for anxiety, externalizing, sex, and age. Follow-up analyses examined six subfactors of emotion dysregulation as multiple mediators of the neuroticism/depression association. Goal directed 
behavior, lack of emotion regulation strategies, and impulse control were significant mediators, controlling for the other three emotion dysregulation sub-factors.

According to Chang WHet al. (2015) the impact of neuroticism on mental and physical health in both sexes. The aims of this study were to explore whether relationships between neuroticism scores and psychosocial indicators as well as metabolic syndrome in a population of incoming university students existed in the different sexes. In total, 4266 incoming students were included in this study. The test battery comprised a self-administered structured questionnaire, including the neuroticism subscale of the Maudsley Personality Inventory, the 12-item Chinese Health Questionnaire, the Chinese Internet Addiction Scale-Revision, the measurement of support functions, and the Pittsburgh Sleep Quality Index. Multivariate logistic regression showed that higher Pittsburgh Sleep Quality Index scores, higher Chinese Internet Addiction Scale-Revision scores, and higher 12-item Chinese Health Questionnaire scores were significantly correlated with neuroticism in both sexes, but lower perceived routine support: measurement of support functions scores were associated only with the male participants. No significant differences were found in terms of body mass index or other metabolic profiles. Individuals with poorer mental health and a poorer personal lifestyle had higher neuroticism scores, and sex effects may influence the scale of perceived social support in the neuroticism group. However, the lack of an association between neuroticism score and metabolic syndrome may be due to the recruitment of younger participants in this study.

According to Marijnissen RM et al. (2014) the risk of depression on incident stroke is conditional upon the relative contribution of vascular disease and of neuroticism in the underlying pathways to depression in a specific patient. We examined whether depression increases stroke in persons with low neuroticism and without preexisting cardiac disease. This was a population-based cohort study with 9-year follow-up $(\mathrm{n}=2,050$; $\geq 55$ years, $52 \%$ female). The incidence of stroke was determined by self-report data as well as data from general practitioners and death certificates. Neuroticism was measured using the Dutch Personality Questionnaire and depression using the Center for Epidemiologic Studies-Depression scale. All data were analysed by Cox proportional hazards regression. A total of 117 incident cases of stroke occurred during follow-up. Among persons with a history of cardiac disease $(n=401)$, depression predicted incident stroke independent of neuroticism level with a hazard ratio $(\mathrm{HR})$ of 1.05 (95\% confidence interval $[\mathrm{CI}] 1.01-1.10)(\mathrm{p}=0.02)$. In persons without cardiac disease $(n=1,649)$, depression and neuroticism interacted significantly in predicting incident stroke $(\mathrm{p}=0.028)$. Stratified analyses showed that depression predicted incident stroke in those with low neuroticism, HR 1.05 (95\% CI 1.00-1.09) ( $\mathrm{p}=0.033)$, but not in those with high neuroticism, HR 1.01 $(95 \%$ CI 0.96-1.05) $(\mathrm{p}=0.82)$.

\section{References}

[1]. M.J. Hettema and associates, (2006),"A population-based twin study of the relationship between neuroticism and internalizing disorders". American journal of Psychiatry, vol.163, no.5,pp.857-864

[2]. M.L. Saulsman and associates, (2004), "The five-factor model and personality disorder empirical literature: A meta-analytic review". Clinical Psychology Review,vol.23,no.8, pp.1055-1085

[3]. Paulus DJ and associates, (2016), "Emotion dysregulation, psychological inflexibility, and shame as explanatory factors between neuroticism and depression."Journal of affective Disorders.vol.10, pp.190-376

[4]. Chang WHand associates, (2015), "The psychosocial indicators related to neuroticism in both sexes: A study of incoming university students." TheKaohsiung journal of Medical Sciences.vol.4, pp. 8-14

[5]. Marijnissen RM and associates, (2014), "Depression in context of low neuroticism is a risk factor for stroke: a 9-year cohort study."Neurology.vol.19,p. 1692 